\title{
Crystallization by local cooling of supercooled sodium acetate trihydrate composites for long-term heat storage
}

Englmair, Gerald; Jiang, Yiliang; Dannemand, Mark; Moser, Christoph; Schranzhofer, Hermann; Furbo, Simon; Fan, Jianhua

\section{Published in:}

Energy and Buildings

Link to article, DOI:

10.1016/j.enbuild.2018.09.035

Publication date:

2018

Document Version

Peer reviewed version

Link back to DTU Orbit

Citation (APA):

Englmair, G., Jiang, Y., Dannemand, M., Moser, C., Schranzhofer, H., Furbo, S., \& Fan, J. (2018). Crystallization by local cooling of supercooled sodium acetate trihydrate composites for long-term heat storage. Energy and Buildings, 180, 159-171. https://doi.org/10.1016/j.enbuild.2018.09.035

\section{General rights}

Copyright and moral rights for the publications made accessible in the public portal are retained by the authors and/or other copyright owners and it is a condition of accessing publications that users recognise and abide by the legal requirements associated with these rights.

- Users may download and print one copy of any publication from the public portal for the purpose of private study or research.

- You may not further distribute the material or use it for any profit-making activity or commercial gain

- You may freely distribute the URL identifying the publication in the public portal 


\title{
Crystallization by local cooling of supercooled sodium acetate trihydrate composites for long-term heat storage
}

\author{
Gerald Englmair $^{\mathrm{a}}$, Yiliang Jiang ${ }^{\mathrm{a}}$, Mark Dannemand ${ }^{\mathrm{a}}$, Christoph Moser ${ }^{\mathrm{b}}$, Hermann \\ Schranzhofer ${ }^{b}$, Simon Furbo and Jianhua Fan ${ }^{\mathrm{a}^{*}}$ \\ ${ }^{1}$ Department of Civil Engineering, Technical University of Denmark, Brovej 118, 2800 Kgs. Lyngby, Denmark \\ ${ }^{2}$ Institute of Thermal Engineering, Graz University of Technology, Inffeldgasse 25/B, 8010 Graz, Austria
}

\section{Highlights}

- Crystallization of supercooled SAT composites started between $-9{ }^{\circ} \mathrm{C}$ and $-24^{\circ} \mathrm{C}$

- Sodium acetate-water mixtures released heat in two stages during crystallization

- Higher, more uniform crystallization temperatures in samples with rusty steel profiles

- Carboxymethyl cellulose and polymeric additives improved heat release during crystallization

- Proof of applicability of $\mathrm{CO} 2$ evaporation and Peltier element devices to initiate crystallization

\begin{abstract}
Sodium acetate trihydrate (SAT) can be used for long-term heat storage in buildings by utilizing its ability to supercool stably to ambient temperatures while preserving its heat of fusion. Additives are used to stabilize the SAT and avoid phase separation. A reliable method for initializing the solidification of supercooled SAT composites is needed to operate a heat storage unit based on supercooled SAT. The crystallization temperatures of SAT composites during cooling were therefore investigated and experiments carried out using methods applying local cooling in a small part of prototype heat storage units to initialize crystallization. To find the crystallization temperatures of SAT composites, supercooled samples were cooled down in a freezer. The influence of rusty metal parts submerged in melted SAT composite samples and various periods at rest in a supercooled state were investigated with regard to supercooling stability and crystallization temperature. Carboxymethyl cellulose, extra water, liquid polymer HD 310, metal-based graphite flakes, and silicone oil were applied as additives to form the different SAT compositions. Samples with $60 \mathrm{~g}$ SAT in glass jars were subject to repeated heating and cooling cycles. It was found that samples containing steel profiles crystallized in the range of -9 to $-15^{\circ} \mathrm{C}$, while SA-water mixtures without steel profiles cooled down to $-24{ }^{\circ} \mathrm{C}$ before crystallizing. Furthermore, samples with carboxymethyl cellulose and liquid polymer HD 310 showed a greater temperature rise during crystallization, which is in accordance with previous findings on heat contents. SAwater mixtures showed a second minor temperature peak at temperatures below $-20^{\circ} \mathrm{C}$, when the sample was cooled down again after the first temperature rise. Devices were developed to initialize the crystallization of supercooled SAT composites in prototype heat storage units using rapid local cooling of the SAT composite. We successfully initialized crystallization by evaporating pressurized liquid carbon dioxide in a small chamber on one side of the PCM container and by using Peltier elements. Our experiments showed that the controlled initialization of crystallization by cooling is feasible for all the SAT composites investigated.
\end{abstract}

Keywords: Sodium acetate trihydrate, stable supercooling, long-term heat storage, $\mathrm{CO}_{2}$ evaporation, Peltier elements. 


\section{Nomenclature}

\section{Dimensional variables}

$\mathrm{T}$

$\mathrm{m}$

$\mathrm{t}$

temperature $\left({ }^{\circ} \mathrm{C}\right)$

mass $(\mathrm{kg})$

time ( $\min )$

temperature difference $(\mathrm{K})$

\section{Greek letters}

$\Delta \mathrm{T}$

\section{Subscripts}

C

CR

Ref

Steel plate

Heat sink

PCM

Surface

$\mathrm{CO} 2$ cooling

crystallization

reference

steel plate attached to a Peltier element

heat sink attached to a Peltier element

phase change material

the surface of the PCM container

carbon dioxide evaporation chamber
$\mathrm{CO}_{2}$

PCM

\section{Abbreviations}

$\mathrm{CMC}$

carboxymethyl cellulose

SA

sodium acetate

sodium acetate trihydrate

carbon dioxide

phase change material

wt.

weight 


\section{Introduction}

\subsection{Long-term heat storage with sodium acetate trihydrate}

Due to the mismatch between solar energy resources and the demand of thermal household services, long-term storage of heat is essential for solar heating systems that aim to cover the heat demand with solar fractions in the range of $80-100 \%$. The concept of a novel compact seasonal heat store based on supercooling of Sodium Acetate Trihydrate (SAT) has therefore been defined in previous research activities at the Technical University of Denmark [1].

SAT, chemical formula $\mathrm{CH}_{3} \mathrm{COONa} \cdot 3 \mathrm{H}_{2} \mathrm{O}$, is a salt hydrate with a melting point of $58{ }^{\circ} \mathrm{C}$. It has been identified as a potential heat storage material due to its relatively high heat of fusion $\left(264 \mathrm{~kJ} \mathrm{~kg}^{-1}\right.$ [2]; 237-243 kJ kg-1 [3]; ) and its relatively high specific heat capacities in both liquid and solid phases [4]. The density of solid SAT in a closed sample that has solidified from supercooled state has been determined to be $1.24-1.28 \mathrm{~kg} \mathrm{~L}^{-1}$ [5]. SAT is attractive for domestic heat storage applications because of its high volumetric heat storage capacity $\left(\sim 500 \mathrm{~kJ} \mathrm{~L}^{-1}\right.$ from $20^{\circ} \mathrm{C}$ in solid state to $80^{\circ} \mathrm{C}$ in liquid state), the low price and its non-toxic properties. Reviews on thermal energy storage with PCM [6], [7] therefore list SAT among the salt hydrates identified for domestic applications.

Supercooling is a phenomenon in which a substance in liquid state cools below its solidifying temperature without solidifying. SAT can be used for long-term heat storage because of its ability to supercool stably to ambient temperatures while preserving its heat of fusion [2], [8], [9]. Once heat is in demand, the solidification of the supercooled solution can be triggered and the preserved heat of fusion will be released as it crystalizes. This has been demonstrated by Dannemand et al. with both flat [10] and cylindrical [11] prototype heat storage units. Flat units have also been used to demonstrate a segmented heat storage in a solar heating system for domestic heat supply [12]. Deng et al. [13] have investigated the performance of a hot water tank that makes use of the stable supercooling of SAT in the mantle.

\subsection{Sodium acetate trihydrate composites}

For utilization of SAT in domestic heat stores, volumes of several cubic meters are needed for solar heating systems with yearly solar fractions close to 1 [1]. For economic reasons chemically pure SAT cannot be used. Instead, industrial SAT products were successfully applied in previous research [10], [12], [14].

Additives are needed to stabilize the SAT in its liquid phase. The solubility of sodium acetate (SA) in the corresponding crystal water at $58{ }^{\circ} \mathrm{C}$ (the melting point of SAT) is not high enough to dissolve all anhydrous salt (experimentally measured by Green [15]). Moreover, as an incongruently melting salt hydrate, SAT suffers from phase separation over repeated heating and cooling cycles and over long periods in supercooled state. Phase separation is caused by the density difference between SA and salt water. When SA molecules settle down to the bottom of a SAT volume and a leaner salt-water solution remains in the upper part of the volume, full reformation of SAT crystals can no longer be achieved [16]. This effect reduces the material's heat storage capacity.

To overcome phase separation, Furbo and Svendsen [17] suggested adding extra water to the salt hydrate. However, tests with prototype storage units [10], [11] showed a decrease in heat capacity after a number of storage cycles had been applied. Thickening agents were therefore used to increase the viscosity of the liquid solution and avoid SA to settle at the bottom of storage units. Carboxymethyl cellulose (CMC) and Xanthan rubber were investigated by Cabeza et al. [3] and Dannemand et al. [15] for this purpose. Liquid polymer solutions have also been identified as able to 
reduce the phase separation effect by increasing the solubility of SAT in the liquid solution [19]. A detailed study on the stability and the heat content of supercooled SAT with various additives was conducted by Kong et al. [14]. Composites containing CMC and the liquid polymer solution HD 310 were found to provide the highest heat of fusion.

Graphite flakes for thermal conductivity enhancement have also been investigated [18]. Oils (paraffin, silicone) that do not mix with SAT have been added to increase heat transfer by filling insulating cavities formed during the solidification and contraction of the SAT composition.

\subsection{Crystallization of sodium acetate trihydrate}

To use SAT as a heat storage material, we need greater understanding of the factors that influence supercooling stability, nucleation mechanisms and crystal growth.

\subsubsection{Supercooling stability}

The crystallization process from pure SA aqueous solution to SAT requires a large degree of supercooling; earlier research found a crystallization temperature of $-15^{\circ} \mathrm{C}$ [20]. The behaviour of SA aqueous solutions has been experimentally investigated and can be explained using phase diagrams [4], [15].

The difference between the actual concentration and the solubility concentration of a solution at a given temperature is called the supersaturation. When an SA aqueous solution supercools, it becomes supersaturated without forming crystals. Supersaturation is the driving force for solution crystallization processes, so a supercooled SA aqueous solution stays in a meta-stable state until nucleation takes place (start of the crystallization process).

In most latent heat storage applications, this phenomenon is unwanted [6], [21]. Measures have even been developed to deliver nucleation centres in order to reduce the supercooling of SAT [22], [23]. Nevertheless, for long-term heat storage, the utilization of supercooled salt hydrates has been studied since the late 1920s [24].

Additives were used to overcome phase separation in liquid SAT and to increase the thermal conductivity of solid SAT. Since pure SAT is too expensive for heat storage applications, impure low-cost SAT products were used to realize large heat storage units in a cost-effective way. And it may well be that the available information on the crystallization properties of SAT, such as phase diagrams, does not apply to SAT composites.

\subsubsection{Nucleation}

Nucleation is the birth of new crystal nuclei. Mullin [25] defined two kinds of nucleation: either from solution (primary nucleation) or in the presence of existing crystals (secondary nucleation).

For primary nucleation, Mullin defined the formation of crystal nuclides from a homogenous fluid as homogeneous nucleation. This is not a common event, because supercooled solutions are probably seeded without our knowledge by the presence of atmospheric dust during material preparation. Because the rate of nucleation of a solution can be affected considerably by the presence of such impurities, this so-called heterogeneous nucleation leads to "spontaneous" nucleation events, the mechanisms of which are not fully understood [26].

A supersaturated solution nucleates much more readily when crystals of the solute are already present or added [25]. Seed crystal injection into a supercooled SAT solution is a secondary nucleation method, which has proved reliable even where there is less supercooling [4], [12]. 


\subsubsection{Crystal growth}

As soon as stable nuclei have been formed in a supersaturated solution, they begin to grow into crystals of visible size. Dietz et al. [27] and Munakata and Nagata [28] have measured the crystal growth rate of supercooled SA-aqueous solutions in tubes. The growth rates were found to be solely a function of the solution concentration and the degree of supercooling. Measured and calculated crystal growth rates have been evaluated by Ma et al. [29], but we do not yet have parameters for the degree of supercooling or models for crystal growth of melted SAT composite material.

\subsection{Mechanisms for the controlled initialization of crystallization}

Heat storage applications that make use of the stable supercooling of SAT need reliable mechanisms for starting crystallization. Several possibilities were tested in laboratory-scale experiments, fewer in setups with volumes of $100 \mathrm{~L}$ or more:

- Adding seed crystals is a common method of initializing the crystallization in SAT in laboratory-scale setups [4], [20], [27]. Crystallization with seed crystals works as long as the crystals do not melt and become inactive [30]. Seed crystal injection in large storage units has been demonstrated by some of the present authors [12].

- Triggering crystallization using ultrasonic waves has been reported as successfully tested [31], but other researchers [32] have stated that it failed.

- Local cooling of SAT in liquid phase down to its crystallization temperature (primary, heterogeneous nucleation). We demonstrated how the cooling power resulting from the endothermic process of evaporating carbon dioxide $\left(\mathrm{CO}_{2}\right)$ could supply a temperature low enough to initiate nucleation in supercooled SAT composites in prototype storage units. Previous studies have shown that SAT will spontaneously crystalize between $-15^{\circ} \mathrm{C}$ and $-25^{\circ} \mathrm{C}[20]$. The phase diagram of $\mathrm{CO}_{2}$ shows a triple point at 5.1 bars at $-57^{\circ} \mathrm{C}$. At atmospheric pressure, the phase change is directly from solid to gas at $-78{ }^{\circ} \mathrm{C}$. This indicates that the temperatures resulting from evaporating $\mathrm{CO}_{2}$ may be low enough to reach the temperature where SAT will crystalize. Dannemand at al. have previously tested prototype heat storage units utilizing the stable supercooling of SAT composites. In their laboratory investigations, they initiated nucleation of SAT in storage units by evaporating $\mathrm{CO}_{2}$ in a small chamber on one side of the PCM unit [1], [10], [33]. The method of using evaporation of $\mathrm{CO}_{2}$ is also used in plumbing to freeze water in pipes to make temporary plugs of ice to enable repairs without draining the entire system.

- Local cooling of SAT in liquid phase using Peltier elements. A setup with a double-element Peltier device reached $-30{ }^{\circ} \mathrm{C}$ and may be able to trigger crystallization [34].

Controlled seed crystal injection requires a rather complex device [12]. If the sealing membranes of the triggering units fail, there could be a risk of unwanted spontaneous solidification in supercooled storage material. In contrast, local cooling of SAT composites using $\mathrm{CO}_{2}$ evaporation or Peltier elements can be done without any moving parts in the supercooled SAT and without penetrating the chamber containing the PCM and is therefore considered a potentially more durable and cost-efficient solution for closed PCM containers. 


\subsection{Scope}

Local rapid cooling of a small part of a PCM storage unit has the potential to be used as a way to initiate the crystallization of supercooled SAT composites. It is therefore crucial to know the temperature at which relevant SAT composites crystalize during cooling. Apart from the additives in the SAT, the vessel containing the SAT composite may work as an impurity, affecting both the behaviour and the crystallization temperature of the SAT. So we investigated and determined the crystallization temperature of various promising SAT composites and of SAT in contact with steel. We also observed whether the length of time that the supercooled SAT composites were kept at $20^{\circ} \mathrm{C}$ had any influence of the crystallization temperature. SAT composites with extra water, CMC, liquid polymeric solution, graphite flakes, and silicone oil were used for the experiments. The results of such investigations have not previously been reported in the literature.

Furthermore, this article includes the measurements and evaluations of two different methods of applying local rapid cooling of a part of the SAT composite volume in supercooled PCM prototype heat storage units: cooling by evaporation of pressurized liquid $\mathrm{CO}_{2}$ and cooling by Peltier elements. Repeated experiments indicate that a reliable initialization of crystallization is possible. Measurements showed when temperatures were achieved that were sufficiently low for application with the various SAT composites. Detailed practical experience of initiating crystallization of supercooled SAT composites using these methods has not been reported previously in the literature. 


\section{Experimental method}

\subsection{Material cooling tests (freezer)}

\subsubsection{Materials}

We used SAT of food grade (European standard 262i) from industrial supply [35]. The material was delivered in bags of $20 \mathrm{~kg}, 4$ months after its production.

To stabilize the SAT, we used CMC and a prototype of a liquid polymer composition provided by Suzhou Hongde Co., Ltd. Jiangsu, China. Demineralised water was used to increase the water content of composites.

To study their influence on the minimum supercooling (nucleation) temperature, we also added graphite flakes and silicone oils to the samples. Table 1 presents the specifications of the materials used.

Table 1. Material properties.

\begin{tabular}{|l|c|c|c|c|c|}
\hline & SAT & CMC & Graphite flakes & Liquid polymer & Silicone Oil \\
\hline Type: & CAS 6131-90-4 & Cekol 30000 & -10 mesh & HD 310 & CAS 63148-62-9 \\
Supplier: & $\begin{array}{c}\text { IG Chemicals GmbH } \\
\text { (GER) }\end{array}$ & CP Kelco (FIN) & Alfa Aesar & $\begin{array}{c}\text { Sushou Hongde Co. Ltd. } \\
\text { (CN) }\end{array}$ & Sigma Aldrich \\
\hline $\begin{array}{c}18.10 .2015 \\
\text { (production date) }\end{array}$ & $\begin{array}{c}09.09 .2013 \\
\text { (production date) }\end{array}$ & no. 43319 & 2016 (prototype) & - \\
$\begin{array}{l}\text { Surity: }>98.5 \%, \\
\text { water contend: } 36-\end{array}$ & - & $\begin{array}{c}\text { purity: } 99 \% \\
\text { (metal basis) }\end{array}$ & $\begin{array}{c}\text { Solid concentratoin: } 40 \%, \\
\text { PH-value: } 4.0, \text { brookfield } \\
\text { viscosity (at } 20^{\circ} \mathrm{C} \text { ): } 1.2\end{array}$ & $\begin{array}{c}\text { density: } 963 \mathrm{~kg} / \mathrm{l} \text { at } \\
25^{\circ} \mathrm{C}\end{array}$ \\
\hline
\end{tabular}

After delivery, the exact water content of the SAT material was measured in dry-out tests. Four open glass cups were prepared with a thin layer $(\sim 2 \mathrm{~mm})$ of crystalline SAT, resulting in four SAT samples with a weight of $20 \mathrm{~g}$ each. The SAT samples were put in a drying oven (Memmert UF55) with a temperature of $120^{\circ} \mathrm{C}$ and air exchange to the ambient. Periodic weight measurements were conducted with a precision scale (linearity: $+/-30 \mathrm{mg}$ ) outside the drying unit. The dry-out tests were repeated with stored SAT 22 months after delivery.

Finely granulated SAT was melted in a closed glass jars at $90^{\circ} \mathrm{C}$ for about 24 hours. To dissolve SA fully, about $1 \%$ wt. demineralized water was added to the granulated SAT. As explained in section 3.1, the SAT delivered showed differences from the molecular SA-water ratio (Fig. 8). The fully dissolved SA aqueous solution (40.5\%wt. water) was referred to SAT.

Then the additives were added to the opened jars and the jars were weighed using a precision scale for individual material configurations. $\mathrm{CMC}$ was added in powder form during stirring, while extra water and liquid polymer were added using pipettes and the materials were thoroughly stirred afterwards. The mass of each additive was set to achieve a certain fraction of the gross-weight of the compositions (Eq.1):

$$
\% w t .=\frac{m_{\text {Additive }}}{m_{S A T}+m_{\text {Additive }}}
$$

The resulting compositions were re-heated in closed glass jars for about 12 hours. Then the samples were put into 50 ml glass jars with polymeric lids. Fig. 1 shows some of the SAT composite samples in solid state from the present work. 


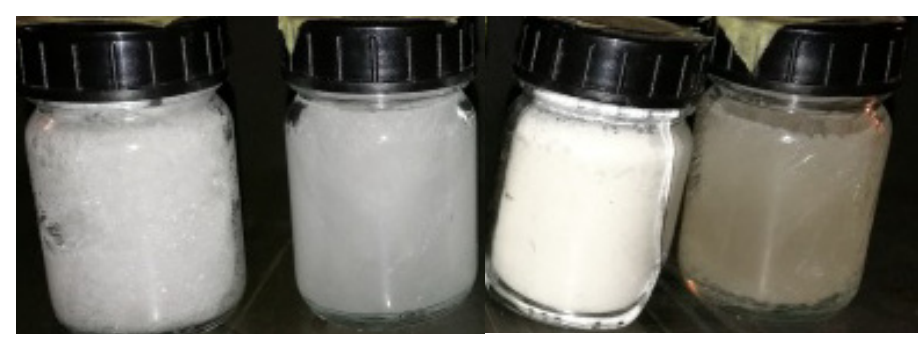

Fig. 1. SAT composite samples after crystallization (from left: SAT, SAT + water, SAT + CMC, SAT + HD 310).

The resulting sample weight depended on the fraction of additive in the mixed composition, based on $60 \mathrm{~g}$ of SAT. Graphite flakes and silicone oil were also added to similarly prepared samples. This approach was chosen to ensure an equal amount of SA in the samples for comparison.

To study the influence of rough metal surfaces, slices of corroded T-profiles of steel (welded connections) were cut with a metal saw and added to samples (Fig. 2b) in 2 batches for separate cooling tests.

An overview of all the samples prepared is presented in Table 2.

Table 2. The material samples investigated, distributed over five batches.

\begin{tabular}{|c|c|c|c|c|c|c|c|c|c|c|c|c|c|c|c|c|c|}
\hline & \multicolumn{3}{|c|}{ Batch 1} & \multicolumn{4}{|c|}{ Batch 2} & \multicolumn{3}{|c|}{ Batch 3} & \multicolumn{4}{|c|}{ Batch 4} & \multicolumn{3}{|c|}{ Batch 5} \\
\hline & $\begin{array}{r}\text { SAT } \\
(\mathrm{g}) \\
\end{array}$ & $\begin{array}{c}\text { Add. } 1 \\
\% w t .\end{array}$ & $\begin{array}{c}\text { Add. } 2 \\
\% \text { wt. }\end{array}$ & \begin{tabular}{|c|} 
SAT \\
$(\mathrm{g})$ \\
\end{tabular} & $\begin{array}{c}\text { Add. } 1 \\
\% \text { wt. }\end{array}$ & $\begin{array}{c}\text { Add. } 2 \\
\% w t .\end{array}$ & $\begin{array}{c}\text { Steel } \\
(\mathrm{g})\end{array}$ & \begin{tabular}{|c|} 
SAT \\
$(\mathrm{g})$
\end{tabular} & $\begin{array}{c}\text { Add. } 1 \\
\% \text { wt. }\end{array}$ & \begin{tabular}{|c} 
Add. 2 \\
$\%$ wt. \\
\end{tabular} & \begin{tabular}{|c|} 
SAT \\
$(\mathrm{g})$
\end{tabular} & $\begin{array}{c}\text { Add. } 1 \\
\% w t .\end{array}$ & $\begin{array}{c}\text { Add. } 2 \\
\% w t .\end{array}$ & \begin{tabular}{|c|} 
Steel \\
$(\mathrm{g})$ \\
\end{tabular} & \begin{tabular}{|l} 
SAT \\
$(\mathrm{g})$
\end{tabular} & $\begin{array}{c}\text { Add. } 1 \\
\% \text { wt. }\end{array}$ & $\begin{array}{c}\text { Add. } 2 \\
\% \text { wt. } \\
\end{array}$ \\
\hline SAT & 60 & - & - & 60 & - & - & 11 & 60 & - & - & 61 & - & - & 9 & 60 & - & - \\
\hline SAT + water & 63 & 9 & - & 60 & 9 & - & 12 & 61 & 9 & - & 60 & 9 & - & 10 & 60 & 10 & - \\
\hline SAT + CMC & 61 & 5 & - & 59 & 5 & - & 13 & 60 & 5 & - & 60 & 5 & - & 9 & - & - & - \\
\hline SAT + CMC + graphite flakes & 60 & 5 & 5 & 60 & 5 & 5 & 13 & 60 & 5 & 5 & 60 & 5 & 5 & 10 & 60 & 5 & 5 \\
\hline SAT + HD 310 & 60 & 3 & - & 61 & 3 & - & 16 & 60 & 3 & - & 60 & 3 & - & 12 & 60 & 3 & - \\
\hline SAT + HD 310 + silicone oil & - & - & - & - & - & - & - & - & - & - & - & - & - & - & 60 & 3 & 4 \\
\hline
\end{tabular}

\subsubsection{Test procedure}

After sample preparation, TT-type thermocouples (copper/constantan) were attached to the outside of the glass jars. They were wrapped 3 times around the glass body and fixed with aluminium tape (Fig. 2a) to ensure good heat transfer. Next, the closed glass jars were evenly insulated with foam insulation (thickness: $15 \mathrm{~mm}$ ) to avoid fast cooling in a cold environment and to achieve more uniform temperatures in the material samples.

The thermocouples positioned on the outer surfaces of the glass jars should have been able to measure the material temperatures because the thin glass wall $(2 \mathrm{~mm})$ had about 20 times greater thermal conductivity $\left(0.9-1.5 \mathrm{~W} \mathrm{~m}^{-1} \mathrm{~K}^{-1}\right)$ than the rather thick foam insulation $\left(0.04 \mathrm{~W} \mathrm{~m}^{-1} \mathrm{~K}^{-1}\right)$. Furthermore, the slow cooling rates ensured a uniform jar temperature, a precise measurement of sample temperatures, and a reduced risk of the glass jars breaking during the expansion and contraction of the samples. The bottom and the mantle insulation (as indicated in Fig. 2a) were glued together, while the cap insulation of the sample containers was fixed with tape.

The thermocouple wires of each batch ( 5 samples at a time) were connected to a portable 10-channel data logger (HIOKI LR8431-20) to ensure continuous logging of temperatures. The ambient air temperature was logged with an additional thermocouple (the $6^{\text {th }}$ channel on the data logger). Measurements were logged at intervals of one second. 

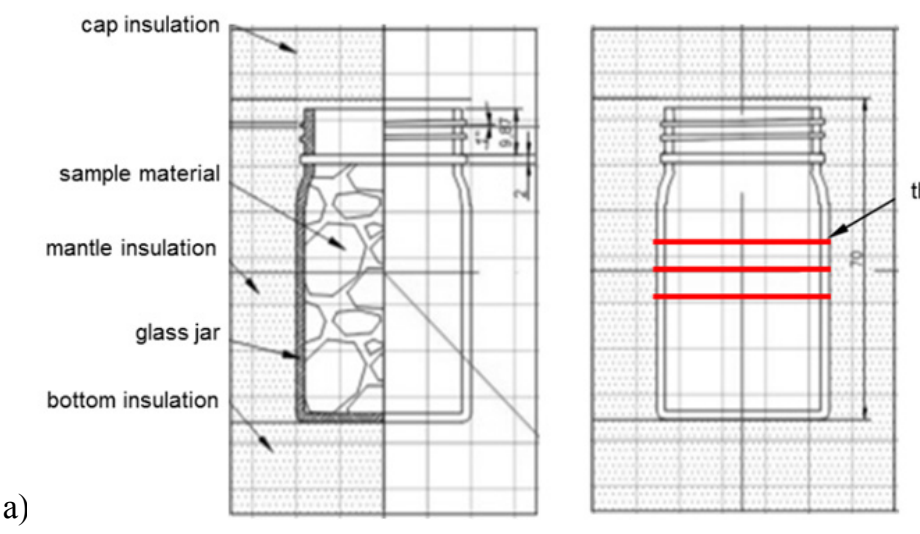

thermocouple wires

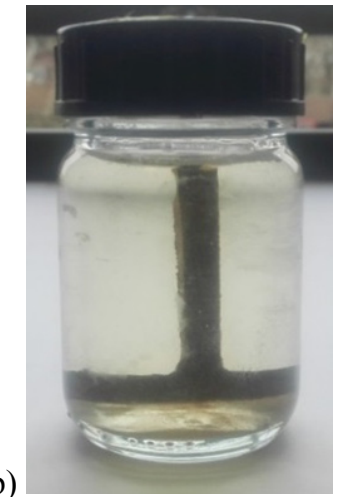

Fig. 2. (a) Sample containment for cooling tests; (b) Glass jar with SAT and sliced steel profile.

To ensure uniform material temperatures, samples were heated in the oven without insulation (placed side-by-side; Fig. 3a) for about 12 hours.

During a cooling down process, the samples were placed in foam insulation and rested, first at room temperature (about $20^{\circ} \mathrm{C}$ ). Then they were put into a freezer (temperature of about $-30^{\circ} \mathrm{C}$ ) with $10 \mathrm{~cm}$ distance to the bottom and the walls, realised using a metal framework (Fig. 3b). The test conditions applied for each batch of samples are given in Table 3.

a)

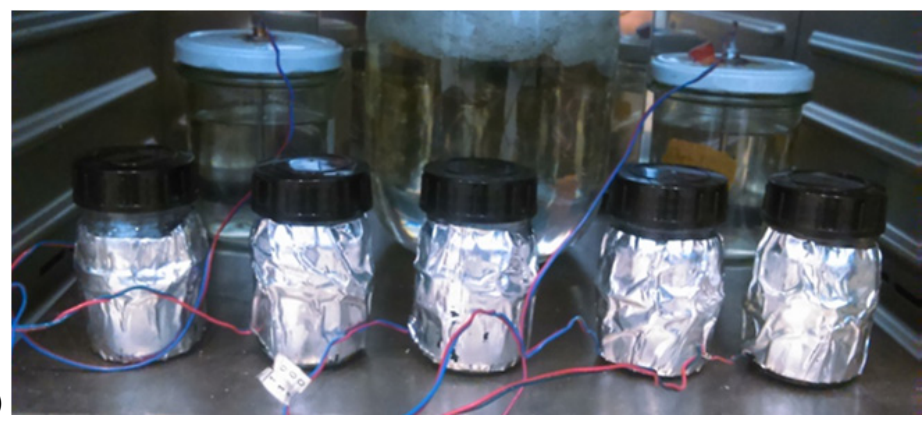

b)

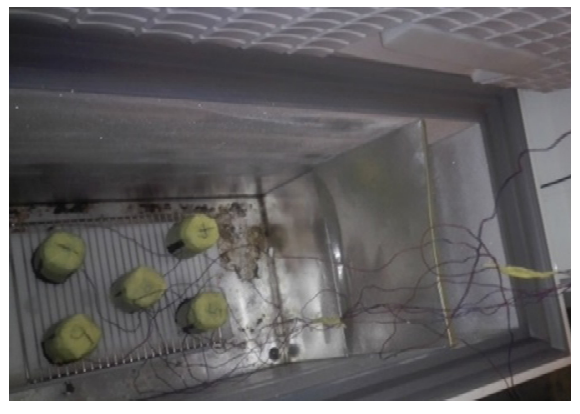

Fig. 3. Photos: (a) Sample placement during heating; (b) Sample placement during cooling.

The cooling process was stopped after 12 hours, when the sample temperatures were no more than $1 \mathrm{~K}$ above the air temperature in the freezer. Next, the samples were kept in their insulation for a period of 4 hours at room temperature before the insulation was finally removed.

\section{Table 3. Test conditions.}

\begin{tabular}{|l|c|c|c|c|c|}
\hline & Batch 1 & Batch 2 & Batch 3 & Batch 4 & Batch 5 \\
\hline Charging temperature $\left({ }^{\circ} \mathrm{C}\right)$ & 90 & 90 & 90 & 90 & 85 \\
Rest period & none & none & 7 days & 8 days & $2 \mathrm{~h}$ \\
Temperature at freezer placement $\left({ }^{\circ} \mathrm{C}\right)$ & $>60$ & $>60$ & $\sim 20$ & $\sim 20$ & $<30$ \\
Steel profile? & no & yes & no & yes & no \\
No. of repetitions & 1 & 1 & 1 & 1 & 4 \\
\hline
\end{tabular}


With batches 1-4, we tested various SAT compositions with different rest periods, cooling temperatures, and with and without the presence of a rusty steel profile in the sample. We found that nearly all the glass jars containing a CMC composition broke due to thermal and mechanical stress. So we decided to produce five more samples, to reduce the heating temperature slightly, and to apply a minimum rest period of 2 hours at room temperature (until the samples cooled down to $30^{\circ} \mathrm{C}$ ) the samples were placed in the freezer. With these samples (Batch no. 5), it was possible to repeat the heating and cooling tests.

\subsubsection{Analysis}

Minimum supercooling temperatures, i.e. crystallization temperatures, were detected when sample temperatures started to rise due to the release of latent heat. We therefore measured the local temperature minima $\left(\mathrm{T}_{\mathrm{CRi}}\right)$ reached in each sample during the cooling process. The first local minimum $\left(\mathrm{T}_{\mathrm{CR} 1}\right)$ was defined as the crystallization temperature. We also measured the increase in the temperature of each sample $\left(\Delta \mathrm{T}_{\mathrm{CRi}}\right)$ after each local minimum, so that we could compare the different samples.

The average logged temperature in the freezer during cooling of the supercooled samples was set as the reference $\left(\mathrm{T}_{\text {ref }}\right)$ for the cooling rate calculation. The start of the cooling periods $\left(\mathrm{T}_{\mathrm{C} 1}\right)$ was set to $45 \mathrm{~K}$ above the reference temperature, while the end of the cooling period $\left(\mathrm{T}_{\mathrm{C} 2}\right)$ was set to $20 \mathrm{~K}$ above the reference temperature. The resulting temperature difference $(25 \mathrm{~K})$ was divided by the duration of cooling in minutes (Eq. 2$)$ to obtain the cooling rate:

$$
\text { cool-down rate }\left(K_{\mathrm{min}^{-1}}\right)=\frac{(T C 1-T r e f)-(T C 2-T r e f)}{t(T C 1)-t(T C 2)}
$$

For example, Fig. 4 shows the approach we chose applied to a cooling curve with SAT $+9 \%$ wt. water. The characteristic temperature levels are indicated.

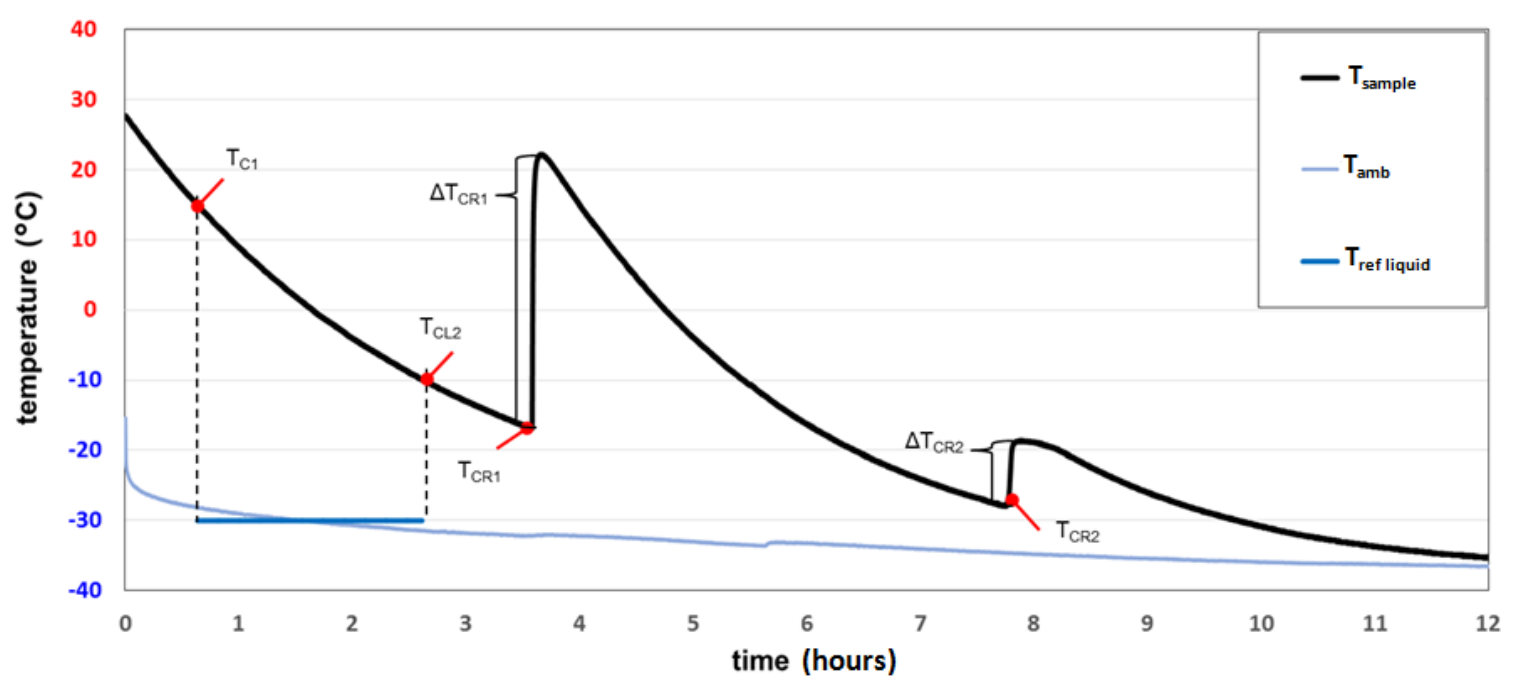

Fig. 4. An example illustrating the evaluation method in the cooling tests (schematic).

\subsection{Initialization of crystallization using $\mathrm{CO}_{2}$ evaporation}

Prototype heat storage units with SAT composites were heated up to $90{ }^{\circ} \mathrm{C}$ and actively or passively cooled down to ambient temperatures under controlled conditions, as described by Dannemand et al. [10]. The prototype heat storage units were $240 \times 120 \times 5 \mathrm{~cm}$ and contained 200-220 kg of SAT composite. In a series of six experiments (overview in Table 5 and section 3.6), the SAT composites in the units were stable in supercooled state at ambient room temperatures 
(about $20^{\circ} \mathrm{C}$ ), before we initiated crystallization by evaporating $\mathrm{CO}_{2}$ in a small chamber adjacent to the chamber with the supercooled PCM.

As shown in Fig. 5, a $\mathrm{CO}_{2}$ cylinder with a dip tube was connected via a rubber tube to the $100 \mathrm{~mL} \mathrm{CO}_{2}$ chamber on one side of the heat storage unit. Another tube was connected to the outlet of the $\mathrm{CO}_{2}$ chamber with a pressureregulating valve including a manometer. The pressure-regulating valve was set to maintain a pressure of approximately 5.5 bars in the tubes and the $\mathrm{CO}_{2}$ chamber. This was to allow the $\mathrm{CO}_{2}$ to remain in liquid phase in the tubes and the $\mathrm{CO}_{2}$ chamber.

The temperatures on the outside of the $\mathrm{CO}_{2}$ chamber $\left(\mathrm{T}_{\mathrm{CO} 2}\right)$, on the side of the $\mathrm{PCM}$ chamber $\left(\mathrm{T}_{\text {surface }}\right)$, and inside the PCM ( $\left.\mathrm{T}_{\mathrm{PCM}}\right)$ were measured using thermocouples (TT-type). The temperature in the PCM was measured in the other side of the PCM chamber, approximately $240 \mathrm{~cm}$ away from the $\mathrm{CO}_{2}$ chamber.

To start the crystallization of the supercooled SAT composite in the heat storage unit, the valve for the $\mathrm{CO}_{2}$ cylinder was opened and the $\mathrm{CO}_{2}$ was flushed through the $\mathrm{CO}_{2}$ chamber until a temperature increase (indicating crystallization) was detected by the nearby temperature sensor $\left(\mathrm{T}_{\text {surface }}\right)$ on the side of the PCM chamber.

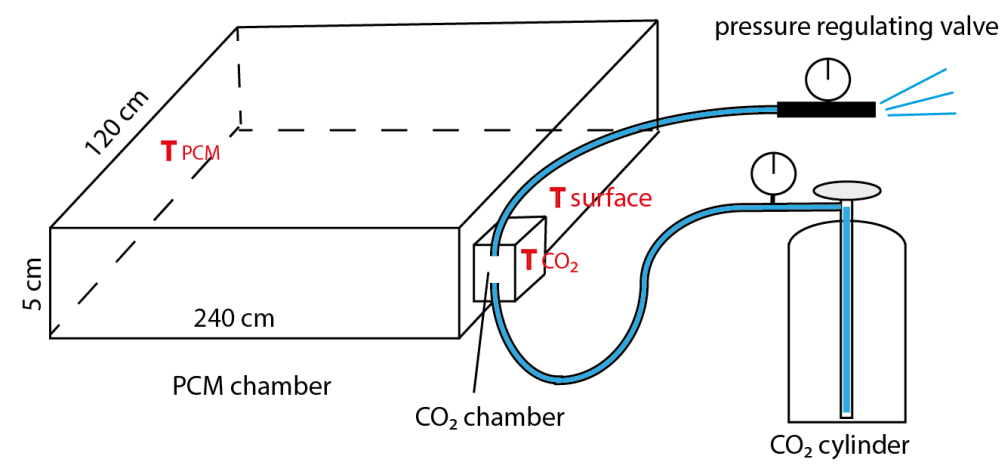

Fig. 5. Principle diagram of the nucleation method using cooling with $\mathrm{CO}_{2}$.

\subsection{Initialization of crystallization using Peltier elements}

Based on previous work by Dröscher [36], we built a novel double-element Peltier device with cooling power of $8.8 \mathrm{~W}$ and $29.7 \mathrm{~W}$ (Fig. 6).

To ensure contact with the PCM, a steel extension pipe with a hole drilled in the bottom was mounted on the Peltier device. The extension pipe was filled with PCM. Rubber sealing ensured air-tightness in the construction. The lower Peltier element was in contact with the pipe via a steel plate. Thermal compound was used to improve the heat transfer to the steel plate. A thermocouple (type K) was placed below the lower Peltier element to measure the temperature of its cold side, which was attached to the steel plate $\left(\mathrm{T}_{\text {steel plate }}\right)$. Above the upper Peltier element, a heat sink was realised with an air cooler mounted, consisting of an electrically driven fan and aluminium fins. The temperature of the heat sink $\left(\mathrm{T}_{\text {heat sink }}\right)$ was measured with a thermocouple. 


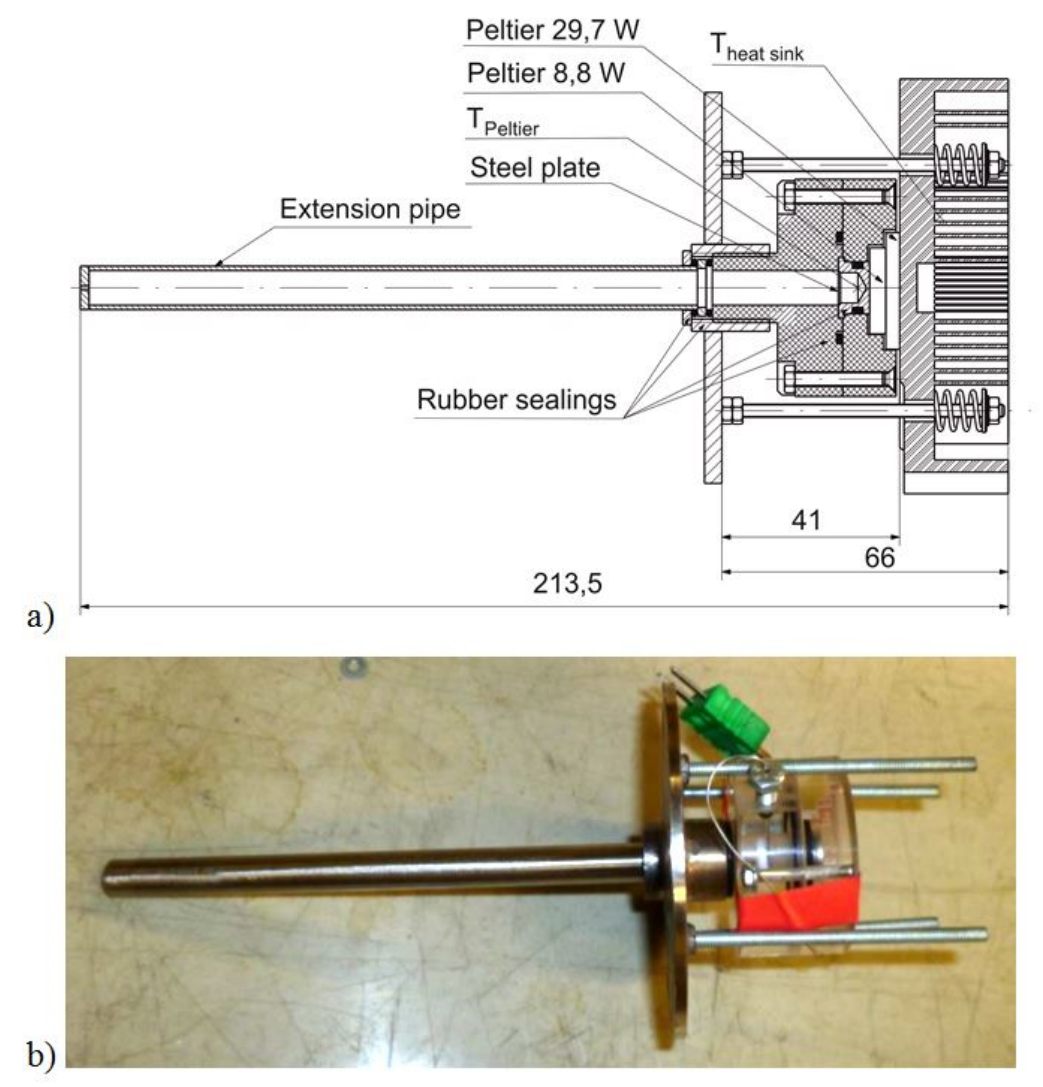

Fig. 6. (a) Drawing of the Peltier device with extension pipe (dimensions in mm);

(b) Peltier triggering device with extension pipe (without the heat sink).

The Peltier device was tested with a small-scale flat heat storage prototype, filled with $5.4 \mathrm{~kg} \mathrm{SAT}+6 \% \mathrm{wt}$. extra water. It was attached via a steel plate to the top-left flange of the heat storage unit (Fig. 7). An additional thermocouple was inserted into the opposite side of the heat storage unit to measure the temperature of the SA-water mixture $\left(\mathrm{T}_{\mathrm{PCM}}\right)$.

The SA-water mixture was heated to $85^{\circ} \mathrm{C}$ and then passively cooled down to room temperature. The power supplies of the two Peltier elements and the fan were turned on until an increase in the temperature $\mathrm{T}_{\mathrm{PCM}}$ indicated the crystallization of the SA-water mixture.

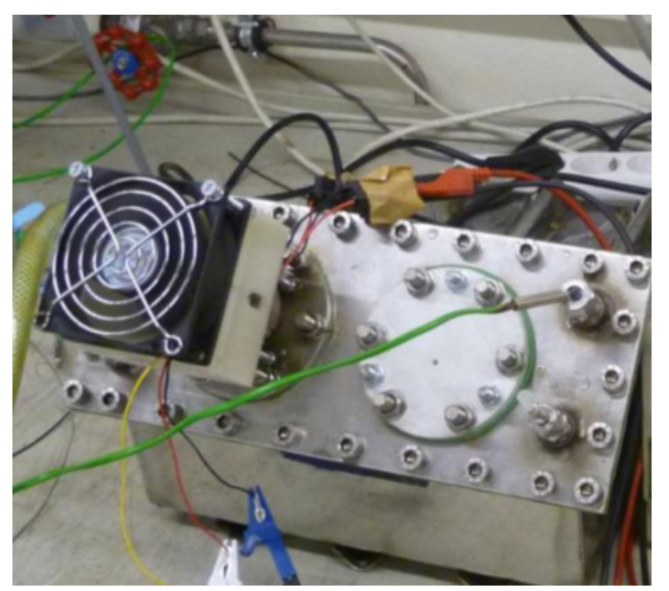

Fig. 7. Photograph of the Peltier device mounted on the small-scale heat storage prototype. 


\section{Results and discussion}

\subsection{Water content of SAT from industrial supply}

Fig. 8 shows the water loss over time during material dry-out. The various water-loss development characteristics of the samples were caused by differences in local temperature and humidity inside the drying oven:

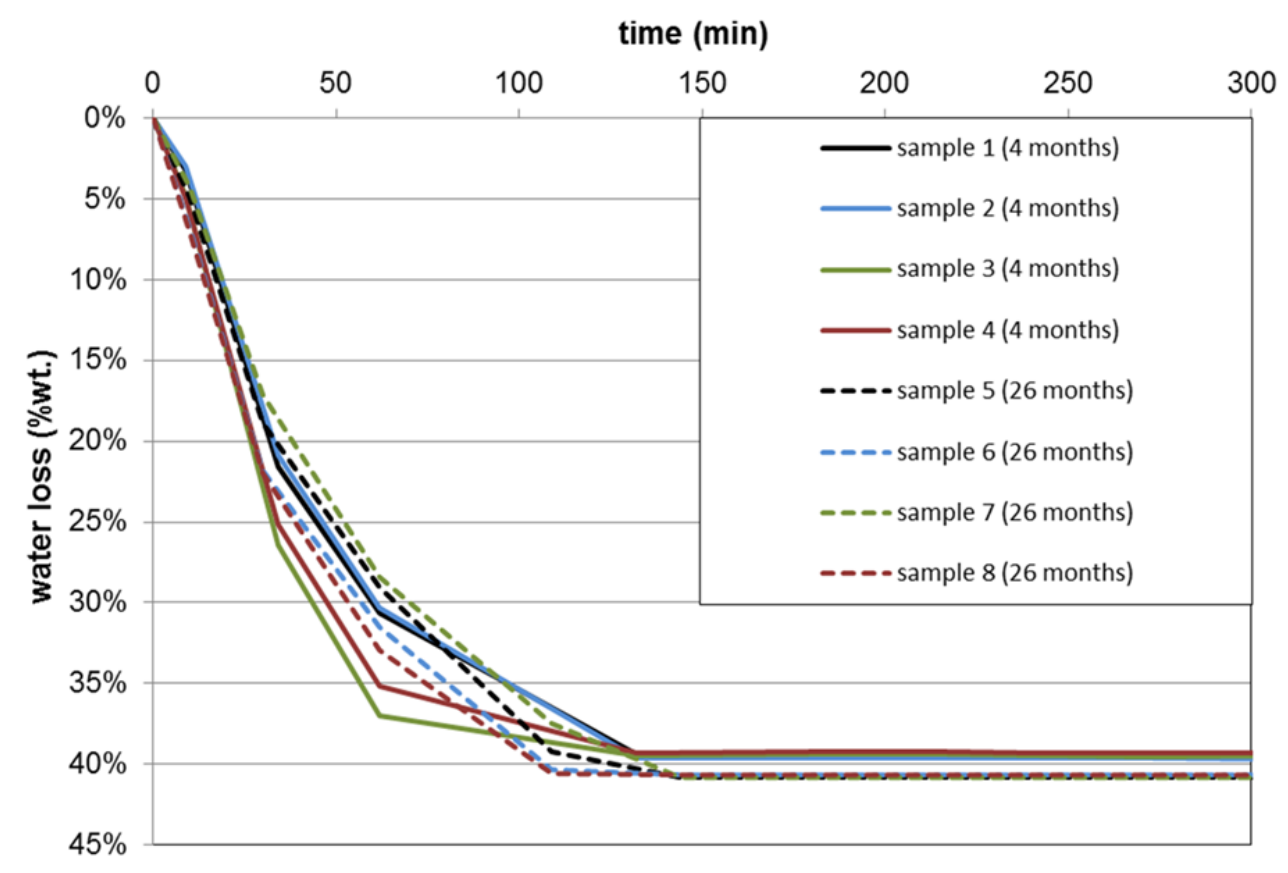

Fig. 8. Drying of SAT samples.

In the case of samples $1-4$, the drying tests were conducted after delivery (4 months after production), and they showed an average water loss of $39.5 \%$ wt. Based on the molar SA-water ratio, the water content of chemically pure SAT is calculated to be $39.72 \% \mathrm{wt}$. Taking the minimal purity of the material into account, the water loss was expected to be $39.12 \% \mathrm{wt}$. (lower benchmark). The influence of scale accuracy on the final weight measurement was calculated to be $+/-0.248 \%$ wt. The mass loss measured therefore indicates the complete dry-out of SAT containing impurities.

After a period of 22 months (26 months after production), samples 5-8 were taken from a SAT bag, which was stored in the laboratory. By this time, the material, which was originally finely granulated particles, had clumped together due to its hygroscopic properties. An average water loss of $40.80 \% \mathrm{wt}$. was measured. This indicates that the water content of SAT from industrial supply strongly depends on the storage conditions.

In this research, SAT was defined with a water content of $40.5 \% \mathrm{wt}$. This value was found to be necessary to fully dissolve SA in water during melting when SAT of food grade (purity $>98.5 \%$ ) was used. The value also includes water vapour losses during the melting of the SA-water mixtures in closed glass jars. 


\subsection{Crystallization behaviour of SA-water mixtures}

In the cooling tests of SAT and SAT with extra water, two stages of heat release were observed. Fig. 9 shows the temperature developments in the SA-water mixtures in four tests with similar conditions. After the initialization of crystallization was detected for the first time $\left(\mathrm{T}_{\mathrm{CR} 1}\right)$, the samples cooled down to a temperature below $\mathrm{T}_{\mathrm{CR} 1}$, until a second temperature increase was measured at $\mathrm{T}_{\mathrm{CR} 2}$.
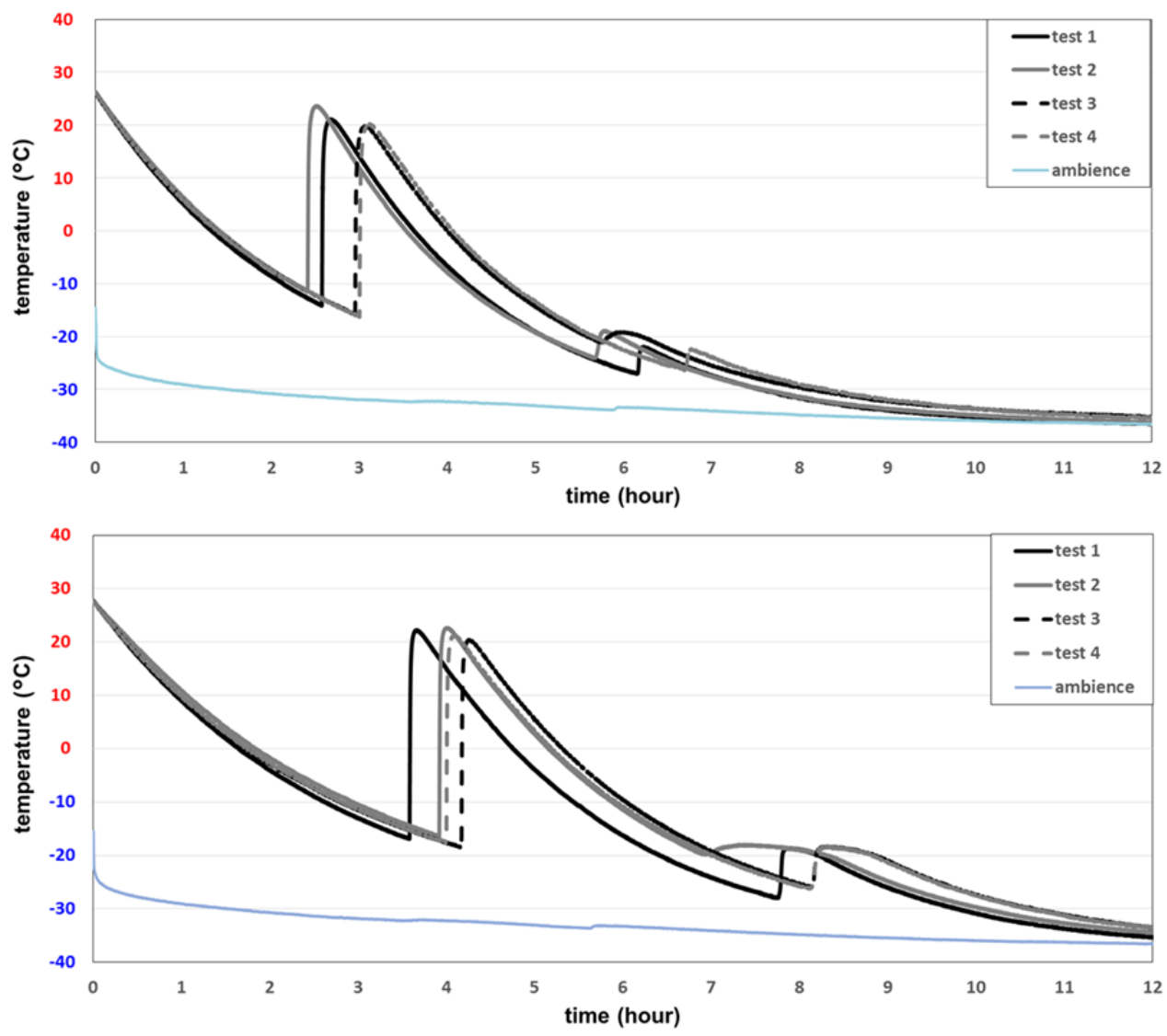

Fig. 9. Crystallization behaviour (sample batch no. 5) in SAT (top) and SAT with extra water (bottom).

As listed in Table 4, with extra water the SA-water mixture cooled down to significantly lower temperatures than any of the other SAT composites (the mean value of $\mathrm{T}_{\mathrm{CR} 1}$ was about $2 \mathrm{~K}$ below the $\mathrm{T}_{\mathrm{CR} 1}$ in other samples). So, extra-water did lower the crystallization temperature. Moreover, the second release of latent heat happened at lower temperatures with this SAT composite.

When the second release of latent heat occurred at a temperature around $-25^{\circ} \mathrm{C}$, a rapid temperature increase was observed. In some cases, the second reaction was initialised at higher temperatures and $\Delta \mathrm{T}_{\mathrm{CR} 2}$ was lower, followed by a longer cooling period. This behaviour indicates that the heat content released during the reaction was similar to when there was a rapid temperature increase. 


\subsection{Crystallization behaviour of SAT with stabilizers}

The composites with $\mathrm{CMC}$ or liquid polymer did not have a second temperature peak during the cooling process. Fig. 10 shows, however, that samples containing stabilizers reached significantly higher temperatures after crystallization started (evaluated in Fig. 13). Afterwards, the SAT composites cooled down over a similar time period (about 8 hours) to the freezer temperature.
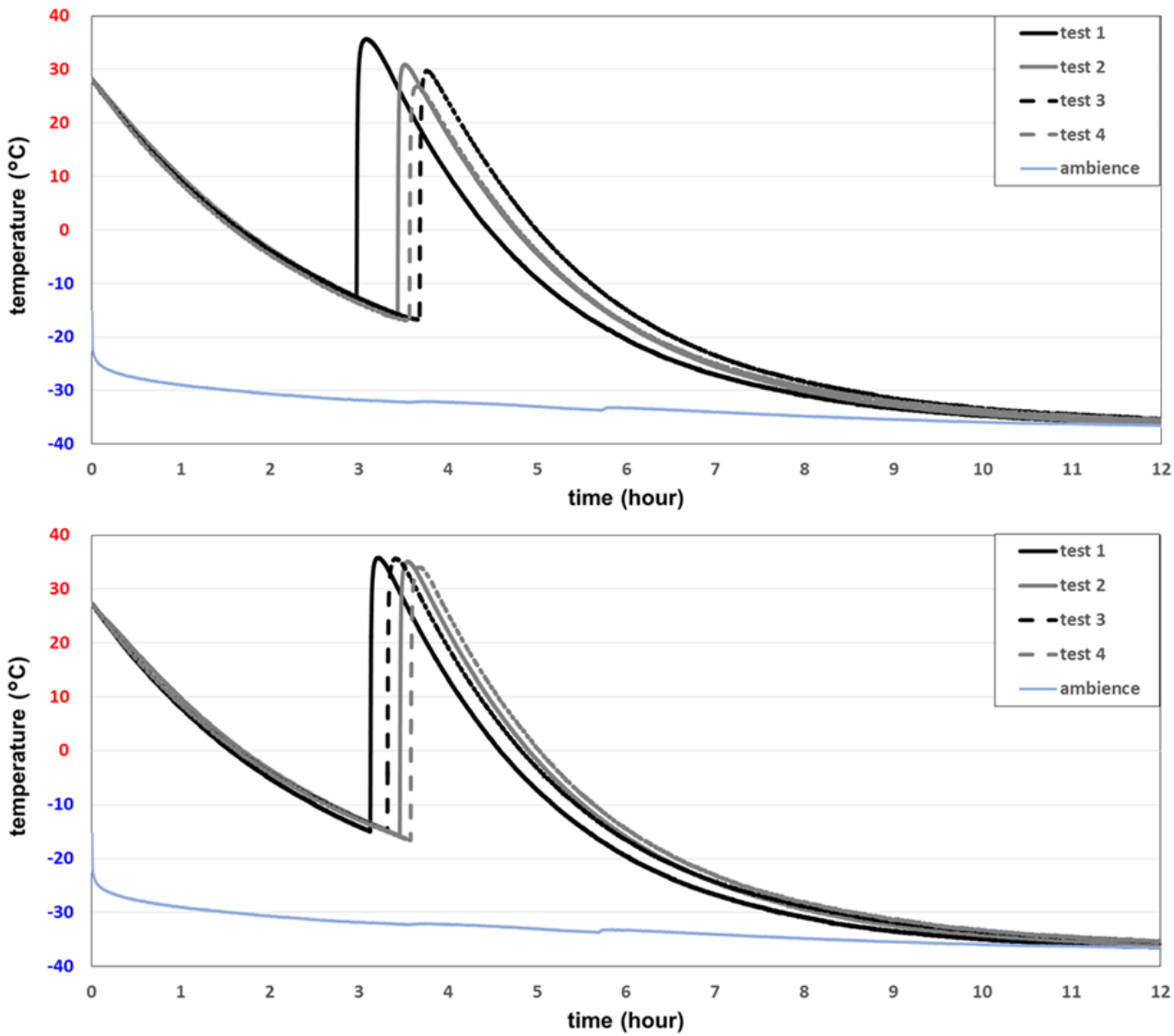

Fig. 10. Crystallization behaviour (sample batch no.5) in SAT +CMC + graphite flakes (top) and SAT +HD 310 (bottom).

The presence of silicone oil in samples containing liquid polymer did not influence temperature developments. As shown in Table 4, four similar heating and cooling cycles revealed no significant tendency for $\mathrm{T}_{\mathrm{CR} 1}$ and $\mathrm{T}_{\mathrm{CR} 2}$ to vary and neither did the type of stabilizer (CMC or liquid polymer) significantly influence $\mathrm{T}_{\mathrm{CR} 1}$ (basis: 12 tests).

\subsection{Influence of steel profiles on the crystallization behaviour}

In parallel tests with various samples containing steel profiles (Fig. 11 bottom), almost uniform crystallization temperatures were detected. As shown in Table 4, crystallization started at higher temperatures. In contrast, samples without steel profiles (Fig. 11 top) showed a big variation in crystallization temperatures, indicated by the time gaps between the crystallizations. 

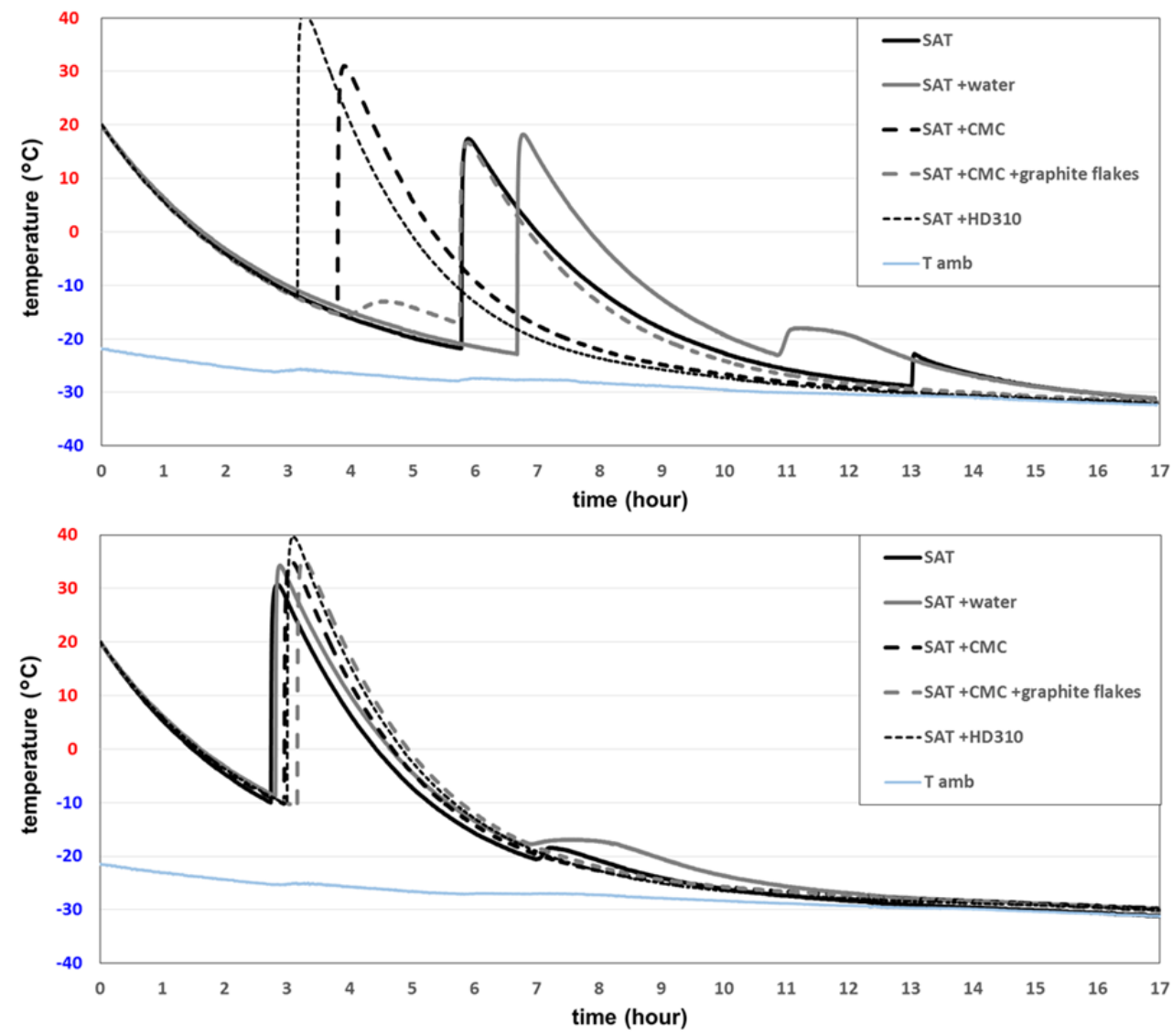

Fig. 11. Crystallization behaviour of sample batch no. 1 (without steel profiles; top) and sample batch no.2 (with steel profiles; bottom).

We found no significant difference in the crystallization behaviour of SAT composites cooled immediately (Fig. 11) and those first given one week of stable supercooling at $20{ }^{\circ} \mathrm{C}$ before cooling (Fig. 12). However, as shown in Table 4, lower crystallization temperatures were observed in samples containing rusty steel profiles that were given the rest period before cooling. 

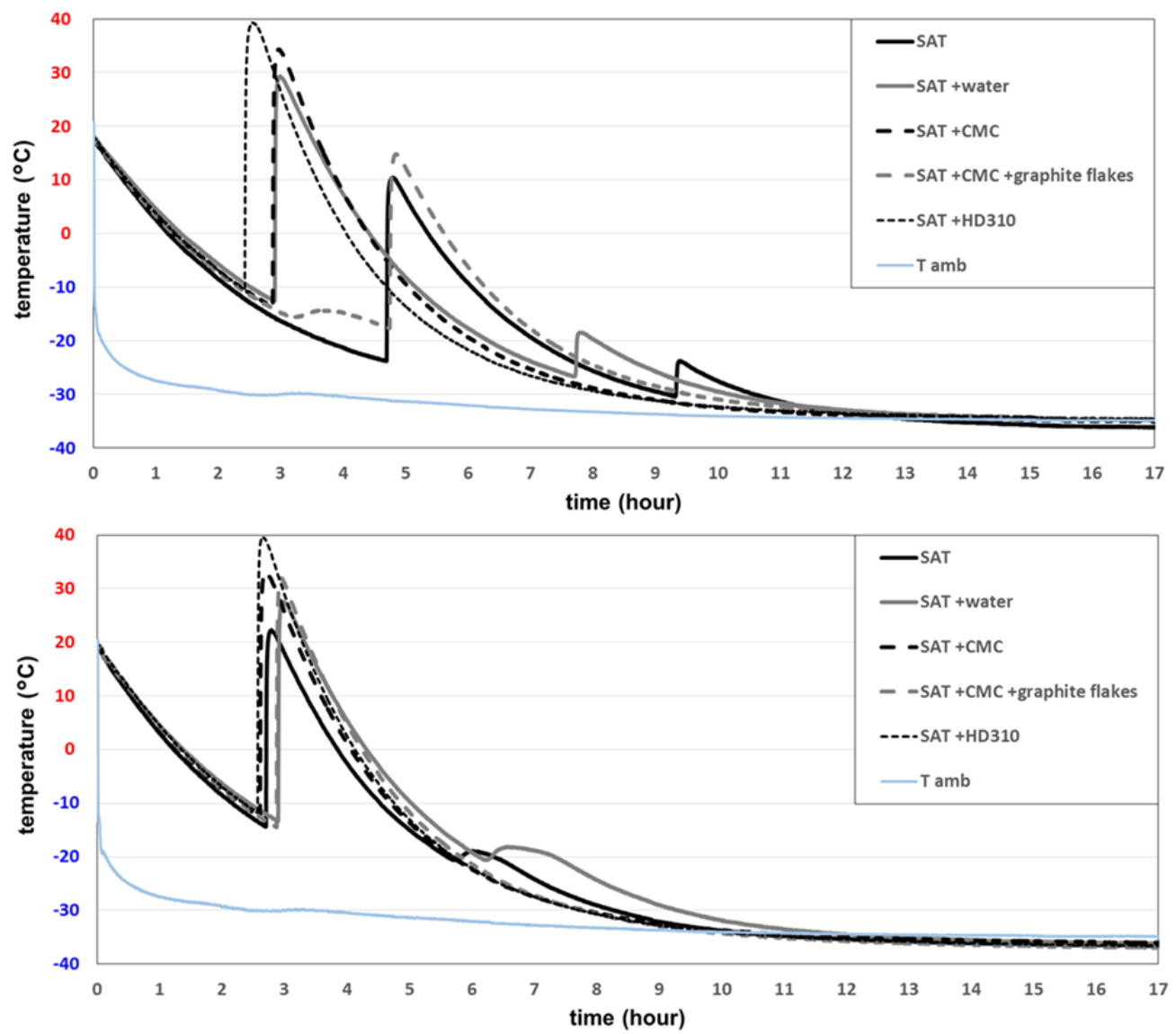

Fig. 12. Crystallization behaviour after one week rest sample batch no. 3 (without steel profiles; top) and sample batch no.4 (with steel profiles; bottom).

\subsection{Cooling test analysis}

Cooling rates varied only slightly in between 0.2 and $0.24 \mathrm{~K} \mathrm{~min}^{-1}$. Samples containing extra water cooled down most slowly, while the SAT only samples showed the fastest cooling. Table 4 gives an overview of the local minimum temperatures in all the tests. Temperature values showing a moderate temperature increase are highlighted in grey.

The random measurement error of the thermocouples used was $+/-0.5 \mathrm{~K}$, assuming a uniform probability distribution. Because measurements were taken every second and the cooling rates were rather low, the temperature measurements are considered to be precise. The position of the sensors means the temperatures measured should be very close to the actual sample temperatures. Moreover, the slow cooling resulted in a graph with a very small slope, which enables us to say that crystallization usually started at about the temperature reported in the literature for pure SA aqueous solutions $\left(-15^{\circ} \mathrm{C}\right)$. However, significantly lower temperatures were measured with Batches 1 and 3 .

During cooling of the samples without steel profiles present, we observed composite-specific ranges for $\mathrm{T}_{\mathrm{CR} 1}$ (and $\mathrm{T}_{\mathrm{CR} 2}$ where applicable). The crystallization of SAT and SAT + water samples (16 tests) started in the range of -11.5 to $-23.0^{\circ} \mathrm{C}$, while in the samples with stabilizers (24 tests), $\mathrm{T}_{\mathrm{CR} 1}$ occurred in the range of -10.7 to $-17.2^{\circ} \mathrm{C}$. The second release of heat for SAT and SAT + water (16 tests) ranged from -17.8 to $-30.4{ }^{\circ} \mathrm{C}$. 
Table 4. Overview of crystallizations temperatures $\left(T_{C R 1}\right)$ and second local minimum temperatures $\left(T_{C R 2}\right)$.

\begin{tabular}{|c|c|c|c|c|c|c|c|c|}
\hline & Batch 1 & Batch 2 & Batch 3 & Batch 4 & \multicolumn{4}{|c|}{ Batch 5} \\
\hline & \begin{tabular}{|c} 
no rest \\
$\left({ }^{\circ} \mathrm{C}\right)$ \\
\end{tabular} & $\begin{array}{c}\text { no rest } \\
\text { steel } \\
\left({ }^{\circ} \mathrm{C}\right)\end{array}$ & $\begin{array}{l}\text { rest } \\
\left({ }^{\circ} \mathrm{C}\right)\end{array}$ & $\begin{array}{l}\text { rest } \\
\text { steel } \\
\left({ }^{\circ} \mathrm{C}\right)\end{array}$ & $\begin{array}{l}\text { test } 1 \\
\left({ }^{\circ} \mathrm{C}\right) \\
\end{array}$ & $\begin{array}{l}\text { test } 2 \\
\left({ }^{\circ} \mathrm{C}\right) \\
\end{array}$ & $\begin{array}{l}\text { test } 3 \\
\left({ }^{\circ} \mathrm{C}\right)\end{array}$ & $\begin{array}{l}\text { test } 4 \\
\left({ }^{\circ} \mathrm{C}\right) \\
\end{array}$ \\
\hline & \multicolumn{8}{|c|}{$T_{C R 1}$} \\
\hline SAT & -21.8 & -10 & -23.8 & -14.4 & -14.2 & -11.5 & -15.8 & -16.2 \\
\hline SAT + water & -22.9 & -8.8 & -12.6 & -14.4 & -16.9 & -16.4 & -18.5 & -17.6 \\
\hline SAT + CMC & -15.3 & -10.2 & -13.7 & -12.6 & - & - & - & - \\
\hline SAT + CMC + graphite flakes & -17.2 & -10.9 & -17.6 & -14.5 & -13.1 & -15.9 & -16.8 & -16.9 \\
\hline SAT + HD310 & -12.1 & -10.3 & -10.5 & -11.7 & -15 & -15.8 & -14.9 & -16.6 \\
\hline \multirow[t]{2}{*}{ SAT + HD 310 + silicone oil } & n.a. & n.a. & n.a. & n.a. & -14.2 & -16.6 & -13.1 & -10.7 \\
\hline & \multicolumn{8}{|c|}{ TCR2 } \\
\hline SAT & -28.9 & -20.6 & -30.4 & -20.5 & -27 & -24.1 & -21.1 & -26.3 \\
\hline SAT + water & -23.0 & -17.8 & -26.7 & -20.5 & -27.9 & -19.7 & -25.9 & -26.2 \\
\hline
\end{tabular}

The samples with steel profiles (10 tests) showed a clear tendency to more uniform and higher $\mathrm{T}_{\mathrm{CR} 1}$ and $\mathrm{T}_{\mathrm{CR} 2}$ values. Crystallization temperatures between -8.8 and $-10.9^{\circ} \mathrm{C}$ were measured for samples cooled without a rest period (5 tests). The second local minimum resulted in a moderate temperature increase.

The samples with steel profiles that had a rest period before cooling ( 5 tests) crystallized at temperatures in a lower range $\left(-11.7\right.$ to $\left.-14.5^{\circ} \mathrm{C}\right)$. There were no significant differences in the local temperature minima in samples without steel profiles that had a rest period before cooling ( 5 tests) and those that did not (5 tests).

Several of the glass jars containing CMC broke. The tests were repeated with Batch 5, when the test procedure had been improved.

In Fig. 13, the blue bars show the average temperature increase in samples during the cooling tests. Here we have excluded the two tests with samples containing CMC and graphite flakes (Fig. 11 top and Fig. 12 top) that did not show a sharp temperature increase when crystallization started.

Because the material volumes of the composite samples (based on $60 \mathrm{~g} \mathrm{SAT}$ ) differed, $\Delta \mathrm{T}_{\mathrm{CR} 1}$ can only be compared in a qualitative way. Nevertheless, a clear order of average temperature increase can be seen: SAT samples showed 36.6 K; SAT + water samples showed 40.3 K; SAT + CMC showed 46.3 K, and 46.5 K with added graphite; SAT + HD 310 showed $50.9 \mathrm{~K}$, and $49 \mathrm{~K}$ with silicone oil added. This order is in good agreement with the heat content for SAT composites measured by Kong et al. [14] using a T-history method. This indicates that CMC and liquid polymer significantly improve the reactivity of SA with water during crystallization. 


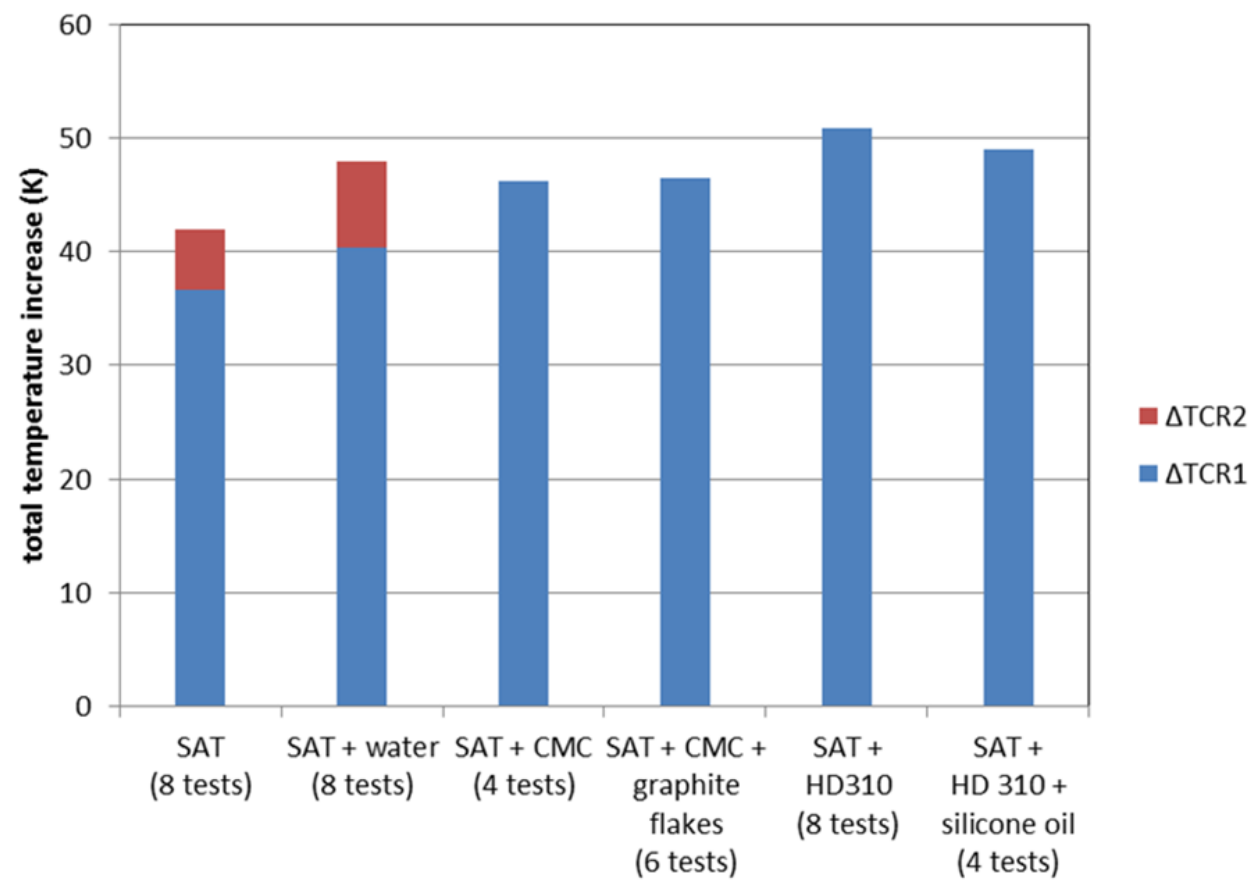

Fig. 13. Comparison of temperature increase during crystallization of material samples.

The second temperature increase $\left(\Delta \mathrm{T}_{\mathrm{CR} 2}\right.$, red bar segments) was derived from samples that showed a sharp temperature increase (10 tests). In 6 out of 16 tests runs, the second temperature peak was reached slowly. The total temperature increase $\left(\Delta \mathrm{T}_{\mathrm{CR} 1}+\Delta \mathrm{T}_{\mathrm{CR} 2}\right)$ was $41.6 \mathrm{~K}$ for $\mathrm{SAT}$ and $48.3 \mathrm{~K}$ for SAT + water samples. This indicates that, due to the very low temperature in these samples, further exothermic crystallization was enabled. This further potential of heat release was not observed by Kong et al. [14] when crystallization took place at $20^{\circ} \mathrm{C}$. We conclude that it can be only utilized when the SA-water mixtures (full volume) are exposed to low temperatures, as in the freezer $\left(-30^{\circ} \mathrm{C}\right)$.

The presence of steel profiles (10 tests) and periods of rest before cooling showed no systematic influence on the temperature increases.

\subsection{Initialization of crystallization using $\mathrm{CO}_{2}$ evaporation}

Six experiments (Table 5) with the initiation of nucleation using cooling by evaporating $\mathrm{CO}_{2}$ were carried out with the prototype units. A temperature range of -27 to $-44{ }^{\circ} \mathrm{C}$ was measured on the outside on the $\mathrm{CO}_{2}$ chamber. After 1.5-5.0 minutes of releasing $\mathrm{CO}_{2}$ into the chamber, a temperature increase was detected at the nearby temperature sensor $\left(\mathrm{T}_{\text {surface}}\right)$ on the surface of the PCM chamber and the valve on $\mathrm{CO}_{2}$ cylinder was closed. The crystallization probably started earlier, because it would take some time for the temperature to increase at the point next to the $\mathrm{CO}_{2}$ chamber where the sensor was. Furbo et al. have reported that supercooled SAT nucleated within 30 seconds of applying the $\mathrm{CO}_{2}$ evaporation method through a $2 \mathrm{~mm}$ metal plate. In their case, the nucleation was observed visually [37]. 
Table 5. Overview of our experiments with heat storage unit prototypes to initialize crystallization using $\mathrm{CO}_{2}$ evaporation.

\begin{tabular}{|l|c|c|c|c|c|c|}
\hline Experiment & $\mathbf{1}$ & $\mathbf{2}$ & $\mathbf{3}$ & $\mathbf{4}$ & $\mathbf{5}$ & $\mathbf{6}$ \\
\hline PCM & $\begin{array}{c}\text { SAT }+ \\
1 \% \text { wt. CMC }\end{array}$ & $\begin{array}{c}\text { SAT + } \\
5 \% \text { wt. water }\end{array}$ & $\begin{array}{c}\text { SAT + } \\
5 \% \text { wt. water }\end{array}$ & $\begin{array}{c}\text { SAT + } \\
1 \% \text { wt. CMC }\end{array}$ & $\begin{array}{c}\text { SAT + } 1 \\
\% \text { wt. CMC }\end{array}$ & $\begin{array}{c}\text { SAT + } 1 \% \text { wt. CMC } \\
+2 \% \text { wt. graphite powder }\end{array}$ \\
\hline Cooling method & active & active & active & passive & passive & active \\
\hline Duration of stable supercooling & 1 day & 5 days & 3 days & 14 days & 71 days & 1 day \\
\hline $\begin{array}{l}\text { Minimum temperature } \\
\mathrm{CO}_{2} \text { chamber }\end{array}$ & $-30^{\circ} \mathrm{C}$ & $-34^{\circ} \mathrm{C}$ & $-36{ }^{\circ} \mathrm{C}$ & $-27^{\circ} \mathrm{C}$ & $-27^{\circ} \mathrm{C}$ & $-44^{\circ} \mathrm{C}$ \\
\hline $\begin{array}{l}\text { Maximum PCM temperature } \\
\text { during solidification }\end{array}$ & $58^{\circ} \mathrm{C}$ & $53^{\circ} \mathrm{C}$ & $53^{\circ} \mathrm{C}$ & $58^{\circ} \mathrm{C}$ & $58^{\circ} \mathrm{C}$ & $58^{\circ} \mathrm{C}$ \\
\hline
\end{tabular}

Fig. 14 shows the development of $\mathrm{T}_{\mathrm{PCM}}, \mathrm{T}_{\text {surface }}$ and $\mathrm{T}_{\mathrm{CO} 2}$ in the heat storage unit during the initialization of crystallization in the supercooled SAT composite in Experiment 1 (1\%wt. CMC). As the PCM composite temperature was measured at the other end of the heat storage unit, approximately $240 \mathrm{~cm}$ from the $\mathrm{CO}_{2}$ chamber, the crystallization and temperature increase occurred there approximately 12 minutes after the nucleation started next to the $\mathrm{CO}_{2}$ chamber. The maximum temperature reached in the PCM after crystallization is also listed in Table 5.

For each nucleation, 700-900 $\mathrm{g} \mathrm{CO}_{2}$ was used. This could probably be significantly reduced with a faster response in relation to when nucleation actually started and an optimized design of the tube and $\mathrm{CO}_{2}$ chamber size.

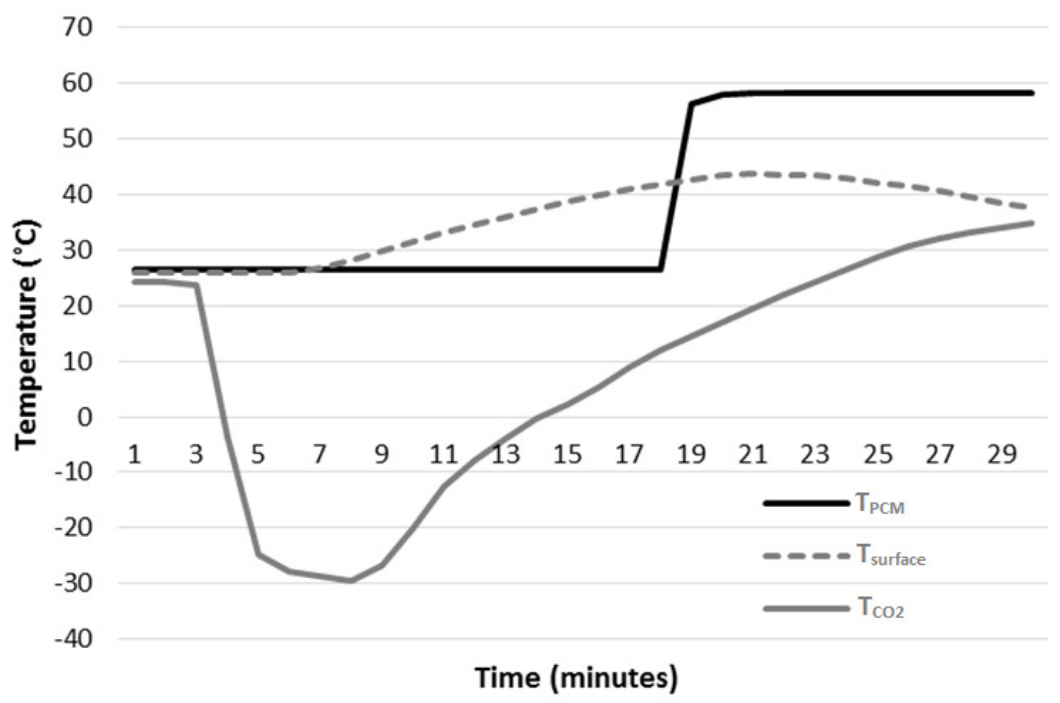

Fig. 14. Temperature development in the $\mathrm{PCM}$, the $\mathrm{CO}_{2}$ chamber and next to the $\mathrm{CO}_{2}$ chamber.

\subsection{Initialization of crystallization using Peltier elements}

Two series of ten experiments each were carried out with the Peltier triggering device. After the SA-water mixture cooled to room temperature, the Peltier device was turned on. The temperature reached in the area of the lower Peltier element $\left(\mathrm{T}_{\text {steel plate }}\right)$ varied from -31 to $-36^{\circ} \mathrm{C}$. Despite the limited cooling power of the Peltier elements, sufficiently low cold-side temperatures were possible when the SA-water mixture supercooled to temperatures below $30^{\circ} \mathrm{C}$.

In the first test series the number of necessary cooling attempts increased till the last experiment, when no crystallization was initiated. The time gap between turning on the Peltier device (first attempt) to measured temperature increase of the PCM varied from 5 minutes to more than six hours at the last experiment. The reason for unsuccessful attempts might be due to the SA-water mixture flowing out of the extension pipe so that no PCM was in contact with 
the steel plate. So we reduced the diameter of the bore-hole at the front of the extension pipe from $1 \mathrm{~mm}$ to $0.4 \mathrm{~mm}$ and the PCM filling volume of the extension pipe from 7.5 to $4.5 \mathrm{ml}$ by adding inert material. The second test series showed 10 successful experiments, in each of which the SA-water mixture crystallized 2.5-7.5 minutes after the Peltier device was turned on.

Fig. 15 shows the temperature developments in Experiment 3 of the second test series. $T_{\text {steel plate }}$ decreased as $T_{\text {heat sink }}$ increased. When $\mathrm{T}_{\text {steel plate }}$ reached $-33^{\circ} \mathrm{C}$, a temperature increase was observed (dotted line in Fig. 15) indicating that the SA-water mixture had started to solidify in the extension pipe. One minute later, the solidification was detected at the temperature sensor in the PCM container $\left(\mathrm{T}_{\mathrm{PCM}}\right)$. During crystallization, the $\mathrm{SA}$-water mixture reached a temperature of $56.5^{\circ} \mathrm{C}\left(\mathrm{T}_{\mathrm{PCM}}\right)$.

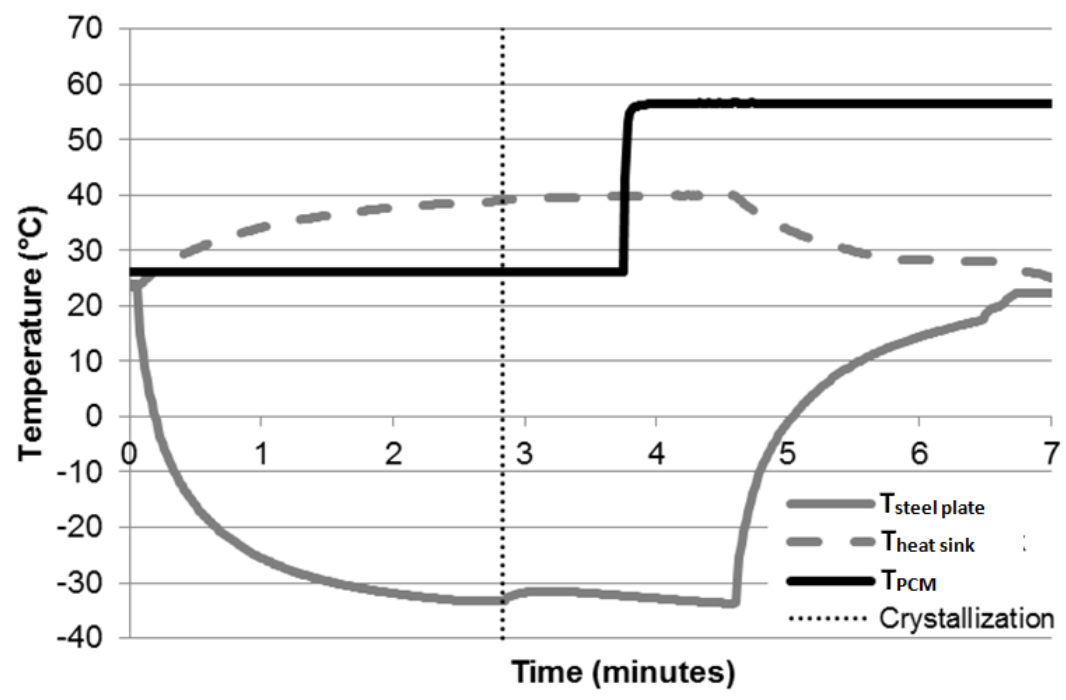

Fig. 15. Crystallization of SA-water mixture by local cooling using Peltier elements.

\subsection{Economic aspects}

For industrial use SAT is available in large quantities. Market prices depend on its purity and are typically below 0.5 Euros per kilogram. Therefore SAT is potentially an economically attractive heat storage material. For economic assessment of heat storage units additives, container, heat exchanger, hydraulics and devices for controlled activation of crystallization need to be taken into account. Rathgeber et al. [38] made a top-down evaluation of acceptable costs of energy storages. They found that acceptable storage capacity costs ranged from about 1 Euro per kWh for seasonal heat storage to 429 Euros per kWh for daily utilization in buildings. Englmair et al. [12] demonstrated that flat prototype heat storage units, utilizing stable supercooling of $200 \mathrm{~kg}$ SAT composites, enable combined short- and long-term heat storage in domestic solar heating systems. Their total heat storage capacity was $27.4 \mathrm{kWh}$. 12 storage cycles per year result by assuming monthly utilization. In this case acceptable costs for such heat storage units range from 200 to 460 Euros. Prototype heat storage units and activation devices used in the presented work need to be further developed to achieve this cost range. Cylindrical unit design [11] is expected to allow reduction of container and heat exchanger costs in comparison to flat units. Peltier elements and $\mathrm{CO}_{2}$ evaporation can potentially initiate SAT composite solidification with inexpensive devices of reduced size. 


\section{Conclusions}

All the SAT composites investigated supercooled to temperatures below $-8{ }^{\circ} \mathrm{C}$, which means they can be considered useful for application as heat storage materials in households. The following temperatures were required for initialization of crystallization of SAT composites:

- $\quad-24{ }^{\circ} \mathrm{C}$ for SAT and SAT with $9 \%$ wt. water added

- $\quad-18{ }^{\circ} \mathrm{C}$ for SAT with $5 \% \mathrm{CMC}$ and $3 \%$ of HD 310 added

- $\quad-15^{\circ} \mathrm{C}$ for all SAT composites in closed steel containers

Extra water added to the SAT resulted in lower crystallization temperatures in comparison to SAT. Experiments on additional impurities in SAT compositions in the form of rusty steel profiles (which could resemble the metal surfaces of the PCM container) showed that crystallization started at higher and more uniform temperatures for all samples. Letting the samples rest at ambient temperature only affected the crystallization behaviour when steel profiles were present.

The cooling tests proved useful for investigating the supercooling stability of SAT composites:

- A second minor temperature peak occurred below $-20^{\circ} \mathrm{C}$ in the SAT composites with no stabilizers added, and the samples cooled further after the first crystallization. When it occurred below $-21.3^{\circ} \mathrm{C}$, a sharp temperature rise resulted. Otherwise, the temperature increase was slow.

- SAT with 9\%wt. extra water showed higher temperature increases during crystallization than SAT on its own.

- SAT composites with stabilizers (carboxymethyl cellulose and liquid polymer HD 310) showed the highest temperature increase when crystallization was initiated, and there was no second temperature peak as a result of the release of heat.

When a large amount of loose crystalline SAT in paper bags is used to prepare composites for heat storage, its water content must be determined. During melting, $40.5 \%$ wt. water content was necessary to fully dissolve SAT of food grade.

To initiate crystallization of SAT composites in heat storage units in a controlled way, evaporating carbon dioxide in a chamber adjacent to a PCM chamber with supercooled SAT composites worked reliably. A device with Peltier elements mounted on a PCM chamber was also able to generate local cooling to sufficiently low temperatures to initiate crystallization for all the SAT composites investigated when the SA-water mixtures had supercooled to temperatures below $30^{\circ} \mathrm{C}$. With both methods, local cooling was realised rapidly, so that crystallization was initiated two to five minutes after the experiments were started.

\section{Declaration of interest}

None.

\section{Acknowledgements}

This research was funded by the European Commission (Grant Agreement N_ 295568) as part of the Seventh Framework Programme of the European Community for Research, Technological Development and Demonstration Activities under the funding scheme of "Collaborative Project" through the COMTES consortium. The work was also supported by the PhD program of the Sino-Danish Center for Education and Research (SDC). 


\section{References}

[1] M. Dannemand, J.M. Schultz, J.B. Johansen, S. Furbo, Long term thermal energy storage with stable supercooled sodium acetate trihydrate, Appl. Therm. Eng. 91 (2015) 671-678.

[2] B. Zalba, J.M. Marín, L.F. Cabeza, H. Mehling, Review on thermal energy storage with phase change: materials, heat transfer analysis and applications, Appl. Therm. Eng. 23 (3) (2003) 251-283.

[3] L.F. Cabeza, G. Svensson, S. Hiebler, H. Mehling, Thermal performance of sodium acetate trihydrate thickened with different materials as phase change energy storage material, Appl. Therm. Eng. 23 (13) (2003) 1697-1704.

[4] N. Araki, M. Futamura, A. Makino, H. Shibata, Measurements of Thermophysical Properties of Sodium Acetate Hydrate, International J. Thermophys. 16 (6) (1995) 1455-1466.

[5] M. Dannemand, M. Delgado, A. Lazaro, C. Penalosa, C. Gundlach, C. Trinderup, J.B. Johansen, C. Moser, H. Schranzhofer, S. Furbo, Porosity and density measurements of sodium acetate trihydrate for thermal energy storage, Appl. Therm. Eng. 131 (2018) 707-714.

[6] A. Sharma, V.V Tyagi, C.R. Chen, D. Buddhi, Review on thermal energy storage with phase change materials and applications, Renew. Sustain. Energy Rev. 13 (2) (2009) 318-345.

[7] J. Pereira da Cunha, P. Eames, Thermal energy storage for low and medium temperature applications using phase change materials - A review, Appl. Energy 177 (2016) 227-238.

[8] J. Xu, R.Z. Wang, Y. Li, A review of available technologies for seasonal thermal energy storage, Sol. Energy 103 (2013) 610-638.

[9] T. Kousksou, P. Bruel, A. Jamil, T. El Rhafiki, Y. Zeraouli, Energy storage: Applications and challenges, Sol. Energy Mater. Sol. Cells 120 (A) (2014) 59-80.

[10] M. Dannemand, J. Dragsted, J. Fan, J.B. Johansen, W. Kong, S. Furbo, Experimental investigations on prototype heat storage units utilizing stable supercooling of sodium acetate trihydrate mixtures, Appl. Energy 169 (2016) 72-80.

[11] M. Dannemand, J.B. Johansen, W. Kong, S. Furbo, Experimental investigations on cylindrical latent heat storage units with sodium acetate trihydrate composites utilizing supercooling, Appl. Energy 177 (2016) 591-601.

[12] G. Englmair, C. Moser, S. Furbo, M. Dannemand, J. Fan, Design and functionality of a segmented heat-storage prototype utilizing stable supercooling of sodium acetate trihydrate in a solar heating system, Appl. Energy 221 (2018) 522-534.

[13] J. Deng, S. Furbo, W. Kong, J. Fan, Thermal performance assessment and improvement of a solar domestic hot water tank with PCM in the mantle, Energy Build. 172 (2018) 10-21.

[14] W. Kong, M. Dannemand, J.B. Johansen, J. Fan, J. Dragsted, G. Englmair, S. Furbo, Experimental investigations on heat content of supercooled sodium acetate trihydrate by a simple heat loss method, Sol. Energy 139 (2016) 249-257.

[15] W.F. Green, The 'Melting-Point' of Hydrated Sodium Acetate : Solubility Curves, J. Phys. Chem. 12 (9) (1908) $655-660$.

[16] H. Kimura, J. Kai, Phase change stability of sodium acetate trihydrate and its mixtures, Sol. Energy 35 (6) (1985) 527-534.

[17] S. Furbo, S. Svendsen, Report on heat storage in a solar heating system using salt hydrates, Thermal Insulation Laboratory, DTU, Kgs. Lyngby, Denmark, Report no.70, 1977.

[18] M. Dannemand, J.B. Johansen, S. Furbo, Solidification behavior and thermal conductivity of bulk sodium acetate trihydrate composites with thickening agents and graphite, Sol. Energy Mater. Sol. Cells 145 (3) (2016) $287-295$.

[19] H.W. Ryu, S.W. Woo, B.C. Shin, S.D. Kim, Prevention of supercooling and stabilization of inorganic salt 
hydrates as latent heat storage materials, Sol. Energy Mater. Sol. Cells 27 (2) (1992) 161-172.

[20] M.A. Rogerson, S.S.S. Cardoso, Solidification in heat packs: I. Nucleation rate, AIChE J. 49 (2) (2003) 505-515.

[21] D. Zhou, C.Y. Zhao, Y. Tian, Review on thermal energy storage with phase change materials (PCMs) in building applications, Appl. Energy, 92 (2012) 593-605.

[22] J. Guion, M. Teisseire, Nucleation of sodium acetate trihydrate in thermal heat storage cycles, Sol. Energy 46 (2) (1991) 97-100.

[23] W. Cui, Y. Yuan, L. Sun, X. Cao, X. Yang, Experimental studies on the supercooling and melting/freezing characteristics of nano-copper/sodium acetate trihydrate composite phase change materials, Renew. Energy 99 (2016) 1029-1037.

[24] G.A. Lane, Solar heat storage latent heat material Vol 1, Boca Raton, Florida, United States: CRC, 1983.

[25] J.W. Mullin, Crystallization, 4th Edition, Oxford: Butterworth-Heinemann, 2001.

[26] H. Machida, T. Sugahara, I. Hirasawa, Relationship between supercooling stability and solution structure in sodium acetate aqueous solution, J. Cryst. Growth 475 (2017) 295-299.

[27] P. L. Dietz, J.S. Brukner, C.A. Hollingsworth, Linear crystallization velocities of sodium acetate in supersaturated solutions, J. Phys. Chem. 61 (7) (1957) 944-948.

[28] T. Munakata, S. Nagata, Electrical initiation of solidification and preservation of supercooled state for sodium acetate trihydrate, in Proceedings of the International Heat Transfer Conference, 2010.

[29] Z. Ma, H. Bao, A.P. Roskilly, Study on solidification process of sodium acetate trihydrate for seasonal solar thermal energy storage, Sol. Energy Mater. Sol. Cells 172 (2017) 99-107.

[30] M.A. Rogerson, S.S.S. Cardoso, Solidification in heat packs: III. Metallic trigger, AIChE J. 49 (2) (2003) 522-529.

[31] K. Seo, S. Suzuki, T. Kinoshita, I. Hirasawa, Effect of Ultrasonic Irradiation on the Crystallization of Sodium Acetate Trihydrate Utilized as Heat Storage Material, Chem. Eng. Technol. 35 (6) (2012) 1013-1016.

[32] M.A. Rogerson, S.S.S. Cardoso, Solidification in heat packs: II. Role of cavitation, AIChE J. 49 (2) (2003) 516-521.

[33] M. Dannemand, W. Kong, J. Fan, J.B. Johansen, S. Furbo, Laboratory Test of a Prototype Heat Storage Module Based on Stable Supercooling of Sodium Acetate Trihydrate, Energy Procedia, 70 (2015) 172-181.

[34] L. Wei, K. Ohsasa, Supercooling and Solidification Behavior of Phase Change, ISIJ Int. 50 (9) (2010) 1265-1269.

[35] IG Chemicals, Specification sheet SAT E262i. Bad Salzuflen, Germany, 2015.

[36] H. Dröscher, Master Thesis: The chemical system of sodium acetate/ water as phase change material (PCM) for the use in seasonal energy storage, Graz University of Technology, 2012.

[37] S. Furbo, J. Dragsted, Z. Chen, J. Fan, E. Andersen, B. Perers, Towards seasonal heat storage based on stable super cooling of sodium acetate trihydrate, in EuroSun Congress Proceedings, 2010.

[38] C. Rathgeber, E. Lävemann, A. Hauer, Economic top-down evaluation of the costs of energy storages- A simple economic truth in two equations, J. Energy Storage, 2 (2015) 43-46. 